Regular Paper

\title{
Cogging Reduction of a Low-speed Direct-drive Axial-gap Generator
}

\author{
Tomoki HASHIMOTO ${ }^{* 1}$, Takashi TODAKA ${ }^{* 1}$, Takeru SATO ${ }^{1}$ Hiroyasu SHIMOJI ${ }^{2}$
}

\begin{abstract}
A lot of studies on reducing cogging torque of permanent magnet machines have so far been carried out. However, the most of them are objected for the radial-gap type machines, which have wide application in various fields. In this study, the various techniques of reduction of cogging torque that can be used in rotor part of an axial-gap generator are examined numerically by using the three-dimensional finite element method. It is shown that the reduction of the cogging torque is difficult in the axial-gap type machine rather than the common radial-gap machine. The analyzed results with the three-dimensional finite element method are compared with ones of a reference model of the axial-gap permanent magnet machine, and the improvements are demonstrated.
\end{abstract}

Keywords: FEM, cogging torque, generator, axial-gap, permanent magnet, double-rotor, direct-drive.

(Received: 24 July 2014, Revised: 30 April 2015)

\section{Introduction}

This paper presents methods to reduce cogging torque of a low-speed direct-drive axial-gap generator, which designed for micro hydro and wind power generation systems. Recently, renewable energies such as micro hydro and wind power attract attention as dispersion type power sources. However, there are no lowspeed generators specialized for the micro hydro and wind power. The mechanical speed-up gears are then usually used to increase the revolution speed up to a rated one of a common generator. It becomes a cause of efficiency reduction of the total generation system and also maintenance such as lubricating oil is indispensable to reduce large noise and to keep security.

Cogging torque is caused by interaction between magnets and stator slots [1-4]. In other words, cogging torque is caused by the variation of the magnetic energy of the field due to the permanent magnet with the mechanical angular position of the rotor. Reducing cogging torque component is vital in permanent magnet machine design process especially at low speed and direct-drive applications $[5,6]$. In order to solve these problems, it is necessary to develop a new low-speed direct-drive generator without the mechanical speed-up gears. We have tried to develop a low-speed direct-drive axial-gap generator and produced a prototype experimentally. In this paper, results obtained in investigations of cogging torque reduction by using the threedimensional finite element method are reported.

\section{Axial-gap generator model as a reference}

The models analyzed in this paper are based on a 12-slot 8-pole double-rotor single-stator axial-gap

Correspondence: Tomoki Hashimoto, Faculty of Engineering, Oita University, Oita, Japan

email: v14e2018@oita-u.ac.jp

${ }^{* 1}$ Oita University ${ }^{* 2}$ Oita Industrial Research Institute generator, as shown in Fig. 1. This type of the axial flux machines is called slotted TORUS machine with back to back gramme-ring type winding [5-8]. The stator comprises an iron core and windings while the rotor comprises a disc back-yoke and fan-shaped surfacemounted magnets [9-16]. The machine parameters are given in Table 1. Parallel stator slot openings are employed to ease manufacturing, modeling and analyzing. This axial-gap generator had the maximum cogging torque of $64.5 \mathrm{Nm}$ and the cogging torque waveforms are illustrated in Fig. 2. Here the Line_A, Line _B, and Line $\mathrm{C}$ show the positions of outer, middle, and inner of the permanent magnet rotor. The cogging torque waveforms of the Line_A, Line _B, and Line _C were obtained as a value in the one side gap. The "Back_All" indicates their summation and "All" indicates sum of the double-rotor gaps.

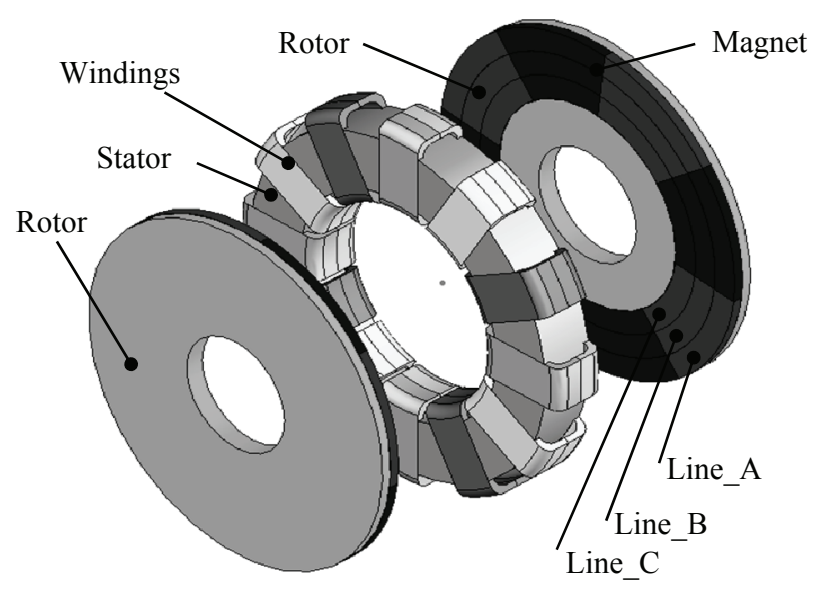

Fig. 1. 12-slot 8-pole axial-gap generator model.

Table 1 Parameters of axial-gap generator model.

\begin{tabular}{|l|l|l|l|}
\hline Number of poles & 8 & Stator outer diameter & $300 \mathrm{~mm}$ \\
\hline Air gap length & $1 \mathrm{~mm}$ & Stator inner diameter & $180 \mathrm{~mm}$ \\
\hline Number of slots & 12 & Total axial length & $89 \mathrm{~mm}$ \\
\hline Number of phases & 3 & Magnet thickness & $8 \mathrm{~mm}$ \\
\hline
\end{tabular}




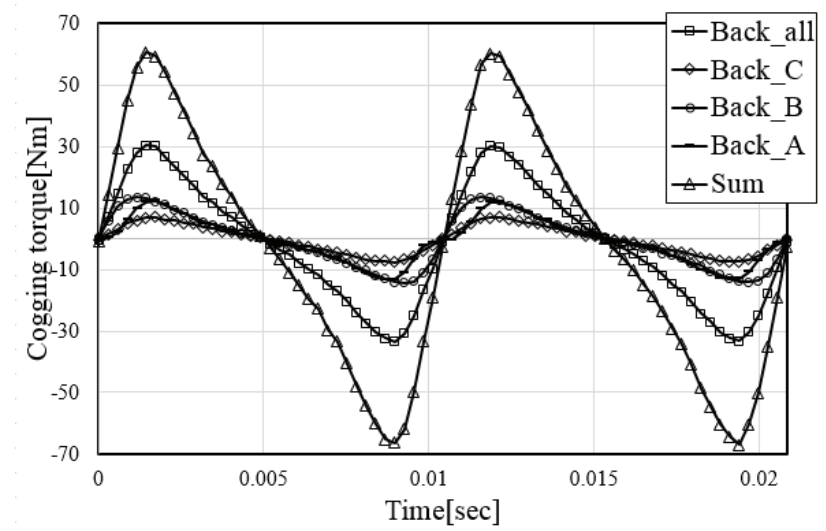

Fig. 2. Cogging torque waveforms of the reference model.

\section{Methods of the cogging torque reduction}

\subsection{Skewing double-rotor}

Because this machine has two rotors in the same construction that the permanent magnets are glued on one side of the disc-type back-yoke, the each rotor can be skewed with a certain angle. In the analysis, we skewed the front rotor in the rotational direction to reduce the cogging torque as shown in Fig. 3. The rotors are faced each other across the stator by keeping the angle from 0 to 7.5 degrees per 1.5 degree step. If the cogging torque waveform distributes as a sinusoidal waveform, it is possible to significantly reduce the maximum cogging torque by canceling each other. However, the axial gap generator of the present study, it has an offset due to position of the peak of the cogging torque waveform as shown in Fig. 2. They are far from a sinusoidal waveform, and then there is a limitation in reducing the cogging torque.

Fig. 4 shows the extracted cogging torque waveforms. As a result, the smallest cogging torque was obtained when the skewed angle was equal to 7.5 degrees as shown in Fig. 5. The cogging torque could be reduced about $66 \%$ in comparing with one of the initial model (0 degrees).

\subsection{Use of angle-sided magnets}

From the results in the previous section, it can be seen that the difficulty is existing in the cogging torque waveform. If we can modify the cogging torque waveform to be a sinusoidal waveform, the total cogging torque should be reduced. Making spaces between the adjacent magnets, it might be possible to change the torque waveform, because it helps to reduce magnetic saturation in the stator and to suppress sudden changes in the magnetic flux density.

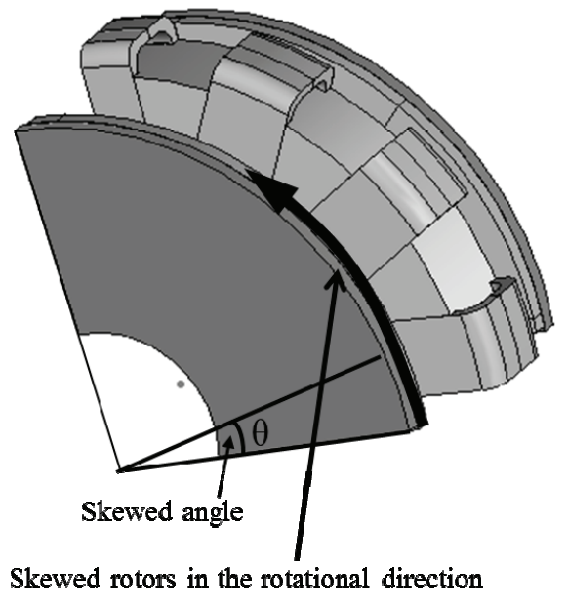

Fig. 3. Skewing the permanent magnet rotors.

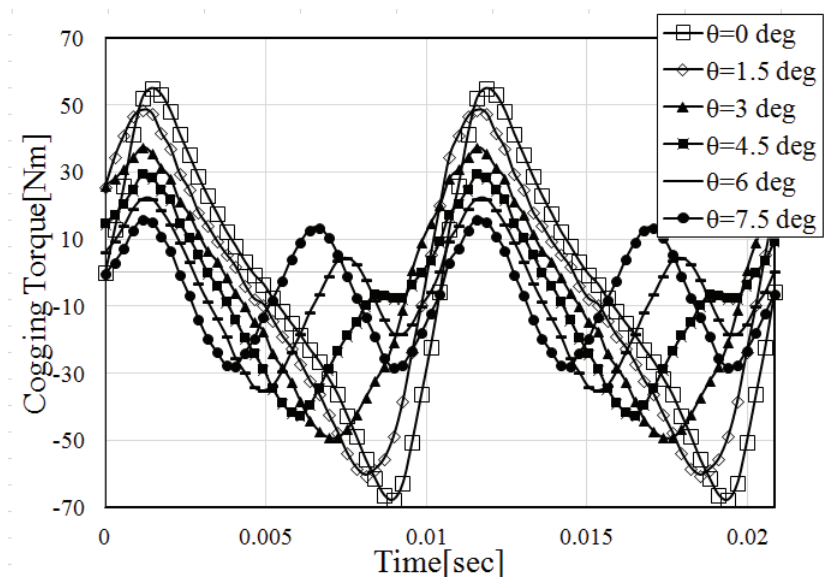

Fig. 4. The extracted cogging torque waveforms.

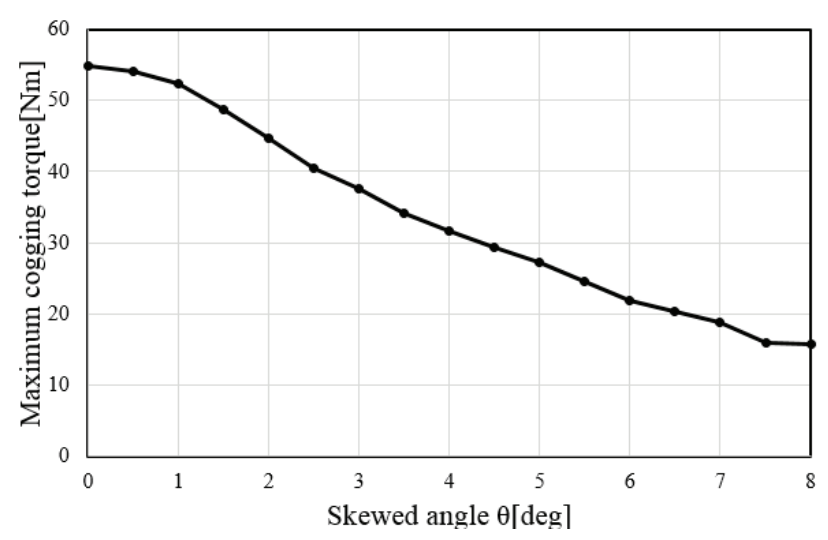

Fig. 5. The maximum cogging torque depending on the skewed angle.

Changing the shape of the permanent magnets is effective and a simple cogging torque reduction technique used in permanent magnet machines frequently. The modification of the shape of the permanent magnets is even easier in axial-gap machines than in radial-gap machines due to their simple and flat surface. 


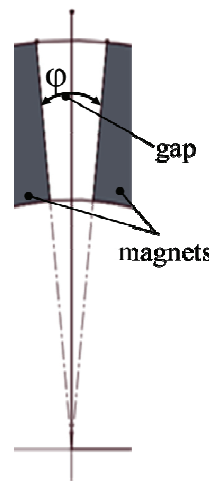

(a)

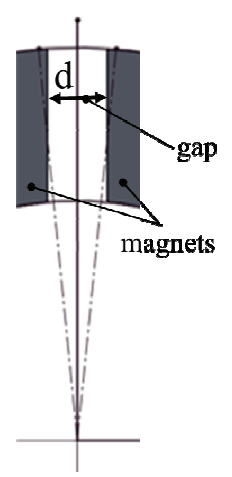

(b)
Fig. 6. Shape of the permanent magnets as a technique of cogging torque reduction: (a) angle-sided magnets, (b) parallel-sided magnets.

In this section, the analysis is performed by changing the space between the adjacent magnets on the basis of the angle, as shown in Fig. 6 (a). Fig. 7 shows the cogging torque waveforms extracted by using the angleside magnets. The maximum values of the cogging torque were not lower than the previous results by skewing as shown in Fig. 8. However, the cogging torque waveforms were approached to a sinusoidal one by opening an appropriate space in angle. It can be confirmed that the distortion factors of the torque waveforms for each angle-side model were changed as shown in Fig. 9. It can be seen that the peak position of the cogging torque waveforms in Fig. 7 was shifted to right hand side by opening the space. It is because the magnetic flux passing mainly through the inner-side of the stator yoke (Line_A) by opening the space changed.

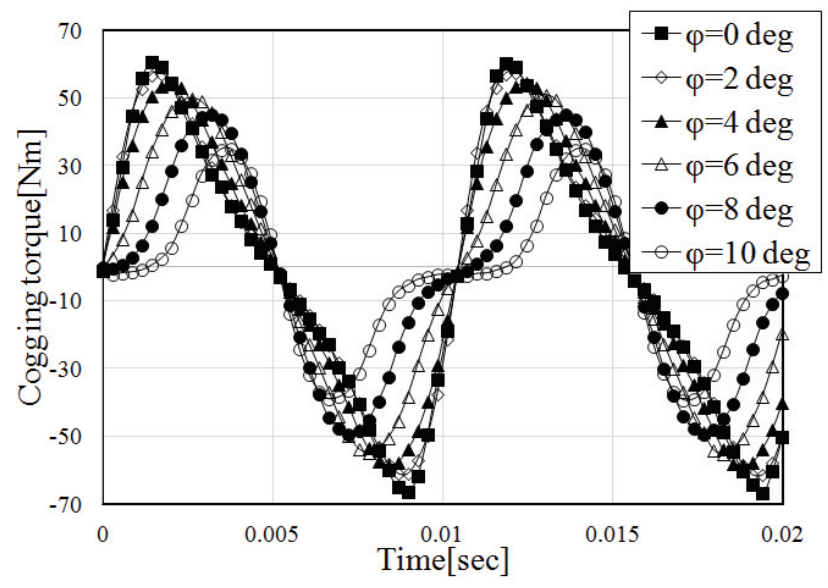

Fig. 7. The cogging torque waveforms extracted by using the angle-side magnets.

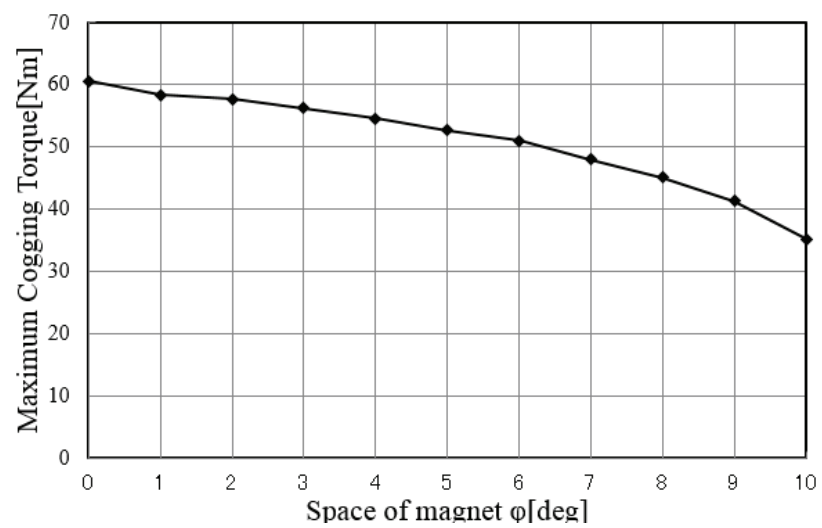

Fig. 8. The maximum cogging torque depending on the angle-space between the magnets.

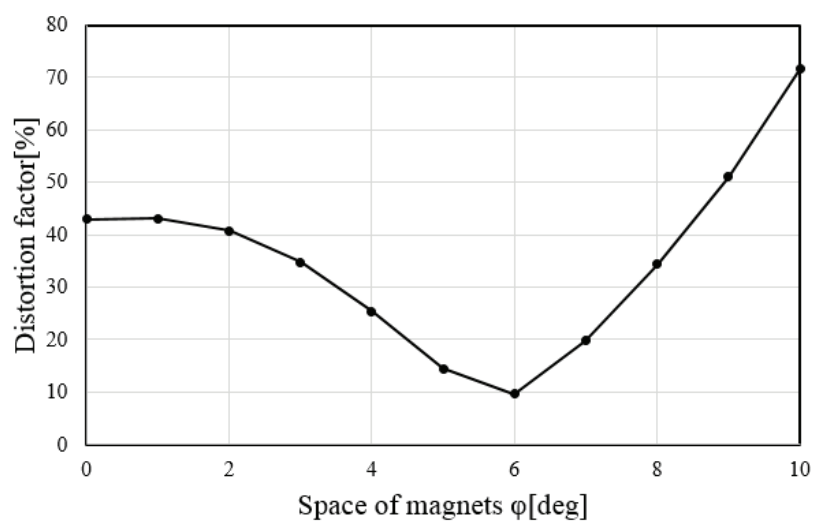

Fig. 9. Relationship between the distortion factor of the torque waveforms and the angle-space between the magnets on the rotor surface.

\subsection{Use of parallel-sided magnets}

To find out more suitable shape of the permanent magnets and space between them in order to approach the torque waveform to a sinusoidal one, in this section we performed magnetic field analysis for the parallelside magnets as shown in Fig. 6 (b). Fig. 10 shows the cogging torque waveforms extracted by using the parallel-side magnets. Fig. 11 shows the maximum cogging torque depending on the parallel-space between the magnets. Fig. 12 shows the relationship between the distortion factor of the torque waveforms and the anglespace between the magnets on the rotor surface. As shown in these figures, the change of the distortion factor and the reduction of the maximum cogging torque showed similar tendency, however, the distortion factor of the model applied the parallel-side magnets was lower than that of the model applied the angle-side magnets. As a result, we judged that the model applied parallel-side magnets, which have $14 \mathrm{~mm}$ gaps was suitable to use in the next step. 


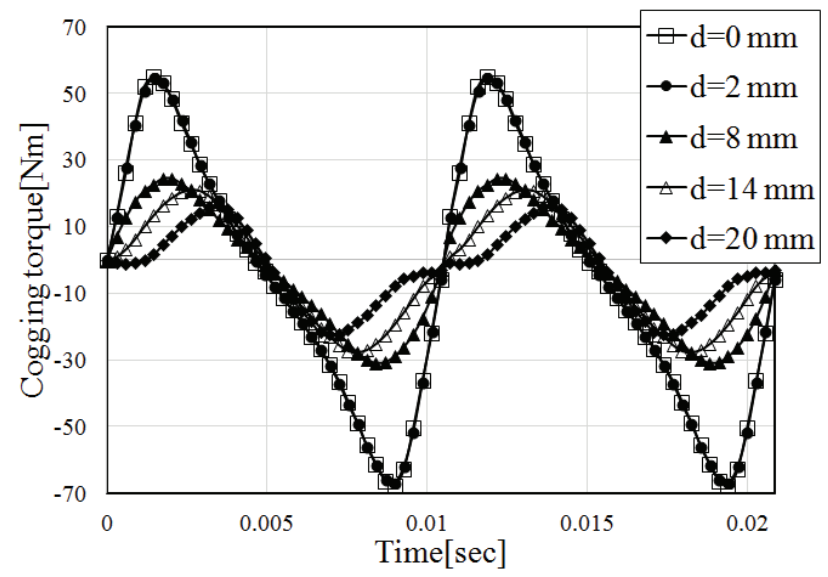

Fig. 10. The cogging torque waveforms extracted by using the parallel-side magnets.

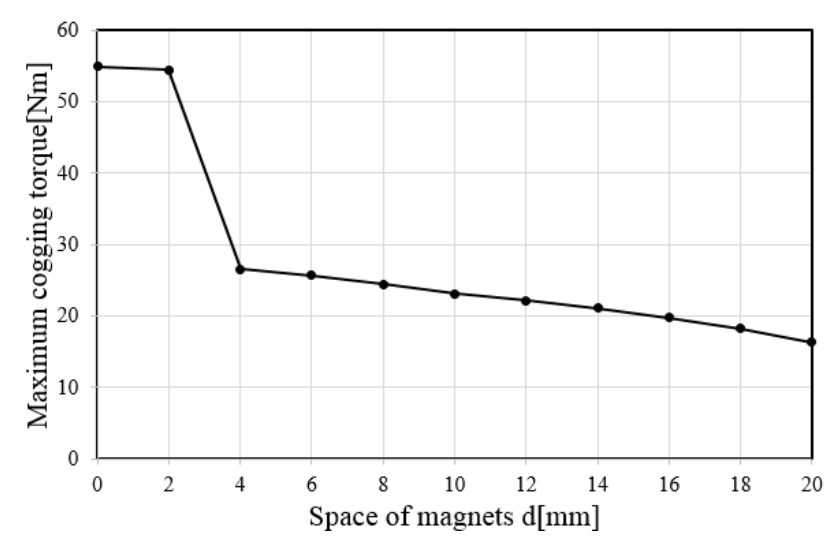

Fig. 11. The maximum cogging torque depending on the parallel-space between the magnets.

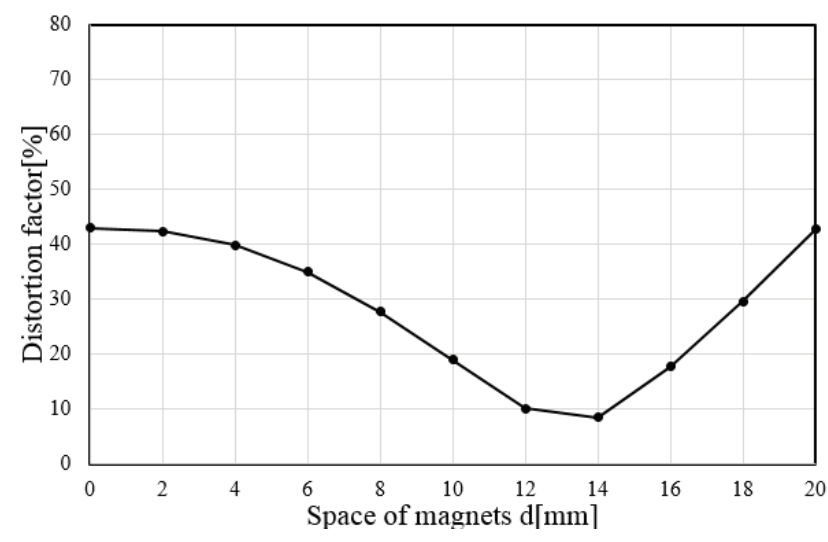

Fig. 12. Relationship between the distortion factor of the torque waveforms and the parallel-space between the magnets on the rotor surface.

\subsection{Results applied the both methods}

As mentioned in the above, the skewing double-rotor was the most effective, however it had limitation to reduce cogging torque due to distortion of the torque waveform. This drawback can be solved by applying both of the skewing and the parallel-side magnet. In this section, we assumed that the model rotors have the 14 $\mathrm{mm}$ opening parallel-side magnets and skewed them 7.5 degree in the rotational direction in order to cancel out the cogging torque generated by the each rotor.

Fig. 13 shows the cogging torque waveform generated by the front rotor, the back rotor and the both rotor. The cogging torque could be reduced up to about 3.2 $\mathrm{Nm}$. In this model, the cogging torque had a negative offset slightly. This is also caused by the distortion of the cogging torque waveform of the both rotors.

Fig. 14 shows the comparison of maximum cogging torque for distortion factor of each model. By combining the methods of the skewing and the parallel-side magnet, the cogging torque was reduced approximately $95 \%$ in comparison with that of the reference model. Fig. 15 shows the comparison of the output power of the last model and the reference model. The output power decreased about $170 \mathrm{~W}$ by reducing the cogging torque. Since the goal of the output power we needed in this study is $700 \mathrm{~W}$, the final model satisfied the target value.

More suitable modification of the shape of the permanent magnets remains as a further problem to improve the cogging torque characteristics.

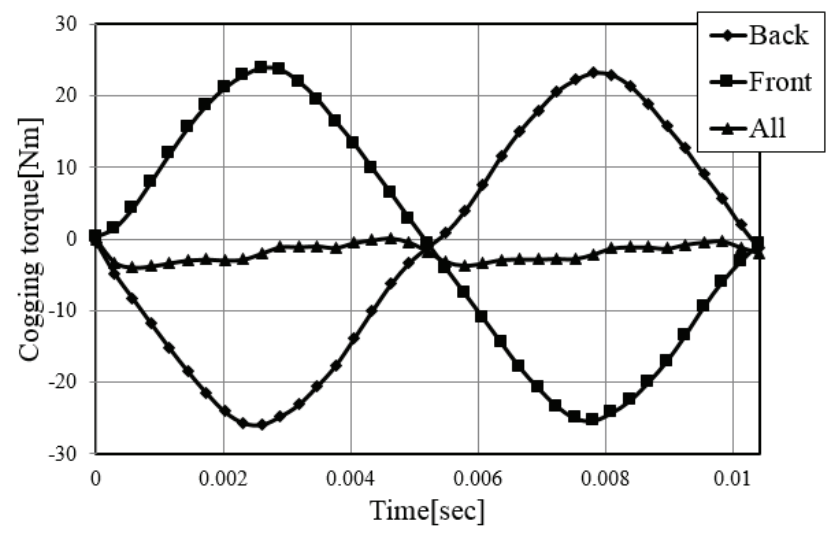

Fig. 13. The cogging torque waveforms generated by the front rotor, the back rotor and the both rotor.

\section{Conclusion}

Some techniques for reducing the cogging torque of the axial-gap generator consisting of the doublepermanent-magnet-rotor, the single-stator and the gramme-ring type stator winding, have been investigated. The effectiveness of the techniques has been examined by using the three-dimensional finite element method.

The skewing double-rotor was very effective in reducing cogging torque and we could achieve the reduction up to $66 \%$ from the reference model. However, it could not entirely offset because the cogging torque waveform was not a sinusoidal one. To overcome this issue and to obtain a sinusoidal cogging torque wave- 
form, we changed space between the adjacent magnets by modifying the shape of the permanent magnets. It made possible to prevent rapid changes of the magnetic flux density in the circumferential direction and magnetic saturations in the stator core, because the magnetic flux flowing in the radial direction was different in the stator core of the axial-gap machine due to the magnetic circuit length. As a result, we could obtain the cogging torque waveform with low harmonic components.

The model combined the $14 \mathrm{~mm}$ opening parallelside magnet and the 7.5 degree skewed rotors showed successfully $95 \%$ reduction of the cogging torque from the reference model. Making a trial to find out more suitable shape of the permanent magnets remains as a further problem.

\section{Acknowledgment}

This work was supported by Oita prefectural research and development project for upbringing energy industry.

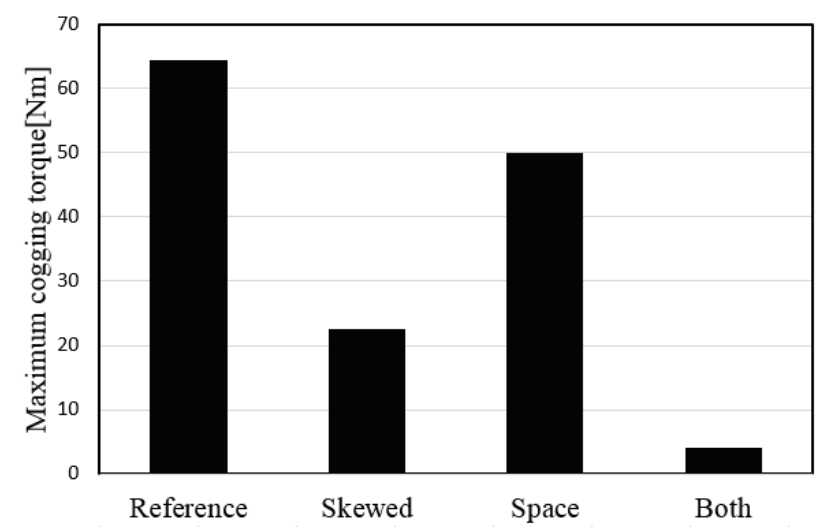

Fig. 14. Comparison of maximum cogging torques of each model.

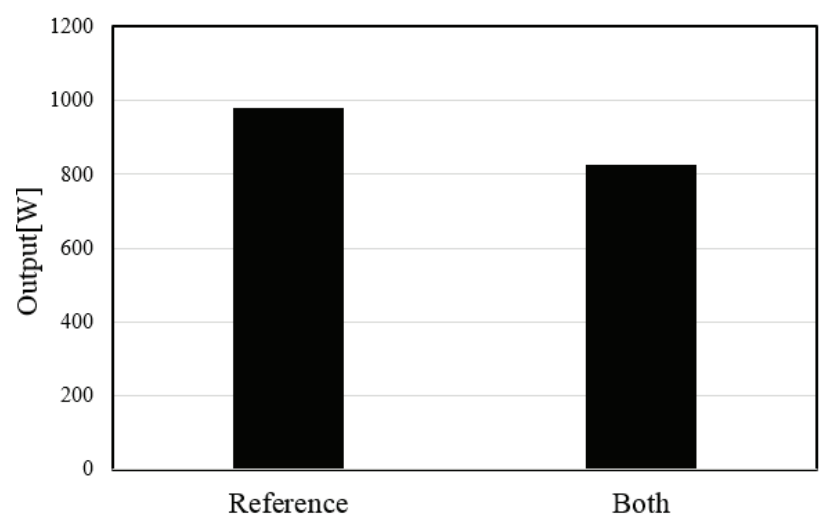

Fig. 15. Comparison of the output power of the last model and the reference model.

\section{References}

[1] C. M. Chao, S. J. Wang, C. P. Liao, D. R. Huang, T. F. Ying, "Torque and cogging torque in sandwich type CDROM spindle machine," IEEE Trans. Magn, Vol.34, No.2, pp.471-473, Mar, 1998

[2] Y. Kawase, T. Yamaguchi, T.Hayashi, "Analysis of cogging torque of permanent magnet machine by 3-D finite element method," IEEE Trans. Magn, Vol.31, No.3, pp.2044-2047, May, 1995.

[3] P. J. Hor, Z. Q. Zhu, D. Howe, "Minimization of cogging force in linear brushless permanent magnet machine," IEEE Trans. Magn, Vol.34, No.5, pp.3544-3547, 1998.

[4] Z. Q. Zhu, Z. P. Xia, D. Howe, P. H. Mellor, "Reduction of cogging force in linear permanent magnet machines," Proc. Inst. Elect. Eng.-Elect. Power Appl, Vol.144, No.4, pp.277-282, 1997

[5] M. Aydin, Z. Q. Zhu, T. A. Lipo, D. Howe, "Minimization of Cogging Torque in Axial-Flux Permanent-Magnet Machines: Design Concepts," IEEE Trans. Magn, Vol.43, No.9, pp.3614-3622, 2007.

[6] M. Aydin, "Magnet Skew in Cogging Torque Minimization of Axial Gap Permanent Magnet Motors," Proceeding of the International Conference on Electrical Machines, Paper ID 1186, 2008.

[7] M. Aydin, S. Huang, and T. A. Lipo, "Torque Quality and Comparison of Internal and External Rotor Axial Flux Surface-Magnet Disc Machines," IEEE Trans. Ind. Electronics, Vol.53, pp.822-830, 2006.

[8] Surong Huang, Metin Aydin, Thomas A. Lipo, "TORUS Concept Machines: Pre-prototyping Design Assessment for Two Major Topologies," IEEE, pp.1619-1625, 2001.

[9] C. S. Koh, H. Yoon, K. Namn, H. Choi, "Magnetic pole shape optimization of permanent magnet machine for reduction of cogging torque," IEEE Trans. Magn, Vol.33, No.2, pp. 1822-1827, 1997.

[10] J. Hur, D. Hyun, "A method for reduction of cogging torque in brushless DC machine considering the distribution of magnetization by 3DEMCN," IEEE Trans. Magn, Vol.34, No.5, pp.3532-3535, 1998.

[11] G. Bakarat, T. El-meslouhi, B. Dakyo, "Analysis of the cogging torque behavior of a two-phase axial-flux permanent magnet synchronous machine," IEEE Trans. magn, Vol.37, No.4, pp.2803-2805, 2001.

[12] R. Qu, T. A. Lipo, "Dual-rotor, radial-flux, toroidally wound, permanent-magnet machines," IEEE Trans. Ind Appl., Vol.39, No.6, pp.1665-1673, 2003.

[13] W. Fei, P. C. K. Luk, "A New Technique of Cogging Torque Suppression in Direct-Drive Permanent Magnet Brushless Machines," IEEE Trans Ind, Vol.46, Oct, 2009.

[14] Goga Cvetkovski, Lidija Petkovsla, Sinclair Gair, Cogging Torque Minimisation of PM Disc Motor by Inserting Stator Slot Closure and Magnet Skewing, PRZEGLAD ELEKTROTECHNICZNY, pp.32-35, 2012.

[15] Z. Q. Zhu, S. Ruangsinchaiwanich, T. Chen, D. Howe, "Evaluation of superimposition technique for calculating 
cogging torque in permanent magnet brushless machines," IEEE Trans. Magn, Vol.42, No.3, pp.1597-1603, 2006.

[16] W. Fei, P. Luk, and K. Jinupun, "A new axial flux permanent magnet Segmented-Armature-Torus machine for in-wheel direct drive applications," IEEE Power Electronics Specialists Conference., pp.2197-2202, 2008. 